\title{
THEORETICAL PROPOSAL OF STEPS FOR THE IMPLEMENTATION OF THE INDUSTRY 4.0 CONCEPT
}

Gabrielly Araújo Cordeiro gcordeiro@fem.unicamp.br University of Campinas - UNICAMP, Campinas, São Paulo, Brazil.

Robert Eduardo Cooper Ordóñez

cooper@fem.unicamp.br University of Campinas - UNICAMP, Campinas, São Paulo, Brazil.

\section{Rodrigo Ferro}

rdgferro@gmail.com

University of Campinas - UNICAMP,

Campinas, São Paulo, Brazil.

\section{ABSTRACT}

Goal: The purpose of this paper is to present a proposal of steps for the implementation of Industry 4.0 in the industrial context, considering management and operational aspects. The reason is to discuss that technological change is accompanied by many organizational implications, in which it is perceivable that some companies already experience strategic and operational turbulence due to the lack of understanding of the this structure's complexity.

Design / Methodology / Approach: This study assumes an exploratory character because the subject of analysis is still in the knowledge-structuring phase. In this sense, data was collected from the literature review.

Results: A theoretical proposal for the Industry 4.0 implementation framework is presented in flow format. It is organized in steps that cover the strategic and operational aspects during the implementation flow.

Limitations of the investigation: The limitations of this study are directly related to its theoretical nature and the difficulty of finding tools that help in the execution of each proposed stage.

Practical implications: However, based on theoretical insights, a trajectory of a transformation model is proposed, thus this research intends to show clearly and direct how companies can introduce the aspects of Industry 4.0 to their own benefit.

Originality / Value: In this study, a conceptual model is structured, and it indicates a potential of application because it contributes to support and encourage the adoption of technologies and concepts indicated in the Industry 4.0 literature in a structured way.

Keywords: Industry 4.0; Digitalization; Smart manufacturing systems; Business strategy. 


\section{INTRODUCTION}

The evolution of production formats has undergone three major transformations marked by previous technological paradigm breaks. A certain accumulation of innovative technologies quantity for applications in manufacturing systems contributes to the occurrence of one industrial revolution movement (Popkova et al., 2019).

In general, the First Industrial Revolution occurred due to the mechanization of production, affecting product volume dimension. The Second Revolution changed the industry through the advent of electricity and mass production. Third Revolution, which remains to this day, is characterized by use of Information Technology (IT) and electronics to process automation (Muhuri et al., 2019; Yin et al., 2018).

Recent discussions are emphasizing the emergence of a Fourth Industrial Revolution, known mainly by the following labels: "Industry 4.0", "Smart Factory", and "Industrie 4.0". The origin of the discussion about Industry 4.0 took place in Germany in 2011; it was based on the country's goal to strengthen the competitiveness of its industry to ensure its future in the advanced manufacturing segment, becoming a reference and providing technologies that allow the integration and interaction between the physical and the virtual world. This initiative was supported by the German government, which announced initial and priority recommendations to accelerate the development and deployment of Industry 4.0. It is worth mentioning that this concept was officially presented in 2013 (Kagermann et al., 2013; Xu et al., 2018).

This theme has gained worldwide recognition and is present in the industrial development plan of countries such as Germany, the United States, China, Japan, South Korea, France, the United Kingdom, Singapore and Brazil (Mancilha et Gomes, 2018; Liao et al., 2017; Zhong et al., 2017).

Industry 4.0 has a remarkable technological potential and can generate a new life style for customers (Muhuri et al., 2019; Oesterreich and Teuteberg, 2016). This structure has a strong basis on data communication made through Internet of Things (IOT) and in the development of self-configuration and self-management of equipment and production systems (Moeuf et al., 2018; Tao et al., 2018). Therefore, an environment of cyber-physical systems is composed, surpassing the paradigm of the interaction between human and technology.

In general, Industry 4.0 provides different ways of managing and controlling the process, contributing to the increase of the flexibility level of the industry and its competitiveness by products mass customization (Yin et al., 2018).

Several technologies and concepts involve the operationalization of this advanced manufacturing scenario, composed of communication, monitoring and data storage systems, scenario simulation, and collaborative and decentralized decision-making. The use of Industry 4.0 technologies in the internal and external environment of companies enables horizontal integration of the entire value chain, full integration of the engineering teams, and a vertical integration of all departments of the company (Kamble et al., 2018; Oesterreich and Teuteberg, 2016).

Kagermann et al. (2013) describes that in parallel with its economic capacity, the use of Industry 4.0 concepts allows development potential due to several positive aspects, such as: meeting a customized demand; process flexibility; optimized decision-making through real time information processing and sharing; efficient use of resources; good levels of productivity; creation of new business opportunities through the provision of services; breaking the demographic barrier and increasing competitiveness.

In contrast to the positive aspects, there are also many challenges that need to be identified so as to minimize deployment risks. Some of the main challenges are high investment in technology and training of people, acceptance of employees, information security, lack of standardization of technology, and regulation (Kagermann et al., 2013; Oesterreich and Teuteberg, 2016; Prause and Weigand, 2016).

In this scenario, technological change is followed by many organizational implications, enabling the development of new business models and greater involvement of employees (Kagermann et al., 2013). Because of positive aspects and technological potential brought by Industry 4.0, it becomes noticeable that some companies are experiencing turbulence at the strategic and operational levels due to the adoption of visionary ideas on the shop floor. The main reason for this is the lack of understanding of the essence, amplitude, and complexity of these new technological concepts (Monostori et al., 2016).

In the research area, Khan and Turowski (2016) reinforce that Industry 4.0 is a relatively recent field for studies. There is variety in the definitions that are formulated according to the understanding and perspective of the discussions conducted by study groups and companies belonging to different contexts (Brettel et al., 2014; Pereira et al., 2018; Khan and Turowski, 2016). The lack of academic and practical consensus may invalidate some applications in this area of Industry 4.0 (Pereira et al., 2018).

Some authors call attention to the small number of citations related to Industry 4.0 when compared to other more specific research areas - Data Mining, for example - which are also involved in this large research area (Monostori et al., 2016; Oesterreich and Teuteberg, 2016). 
However, the number of publications is increasing. Zhong et al. (2017), in a literature review of Industry 4.0, highlight in their analysis a significant increase in research between 2014 and 2015. Monostori et al. (2016) indicate in their work that in a research in scientific database using the terms "cyber-physical system" and "cyber-physical system and manufacturing", which are core concepts of Industry 4.0, the increase in publications from 2010 was noticeable. Moreover, they highlighted that by the year 2015, the increase in publications was approximately eight times greater. The authors project that this trend will continue for the next years.

In addition, studies need to be structured to map the potential use of technologies and their implications for the economy, society, companies, people, processes, environment, and ethics, which makes this context markedly complex (Oesterreich and Teuteberg, 2016).

Some of the proposed implementation structures of Industry 4.0 are focused on the areas of processes and technologies, that is, they only consider technical aspects. There is a research gap regarding proposals for the implementation of the Industry 4.0 steps focused mainly on the areas of business models and implementation methodology, especially so that the management aspects are considered in order to choose the structure that most adds value to the company (Pereira et al., 2017).

Considering these technological contributions and the necessity of companies to adapt to the digitalization environment and the development challenges in the strategic and operational domain, a question arises: how can companies be guided throughout the implementation of their Industry 4.0 projects?

Therefore, the present research aims to propose a theoretical implementation framework for Industry 4.0, considering management and operational aspects. In order to do so, this paper will provide a literature review to support both the core concepts involving the Industry 4.0 scenario and the details of each structured step.

In addition, the main contributions of this research are to stimulate the development of knowledge and technological transition oriented in the research area as well as in the industrial environment. Moreover, it provides a conceptual reference model that can be employed to guide projects and implement the aspects of Industry 4.0 in a structured way.

This paper is organized as follows. Section 2 presents the general context of Industry 4.0, its key technologies, and strategic and operational aspects. Section 3 describes the method adopted in this research. Section 4 presents the theoretical formulation of the implementation flow, the principle of operation, and detailing of the activities. Finally, Section 5 is composed of the final remarks and also shows the limitations and future proposals.

\section{BACKGROUND RESEARCH}

\section{Industry 4.0}

In general terms, Industry 4.0 consists of a new format of organization and control of the whole value aggregation system, whose main objective is to satisfy a demand of customized production at the price of a mass production process (Monostori et al., 2016). It transforms traditional systems into intelligent ones through the support of new models, forms and methodologies (Zhong et al., 2017).

To implement the structure of Industry 4.0, it will be necessary to structure a business model that is aligned with the operation of cyber-physical systems, which will connect and share data in real time between the entire chain. Figure 1 gives a simplified overview of Industry 4.0.

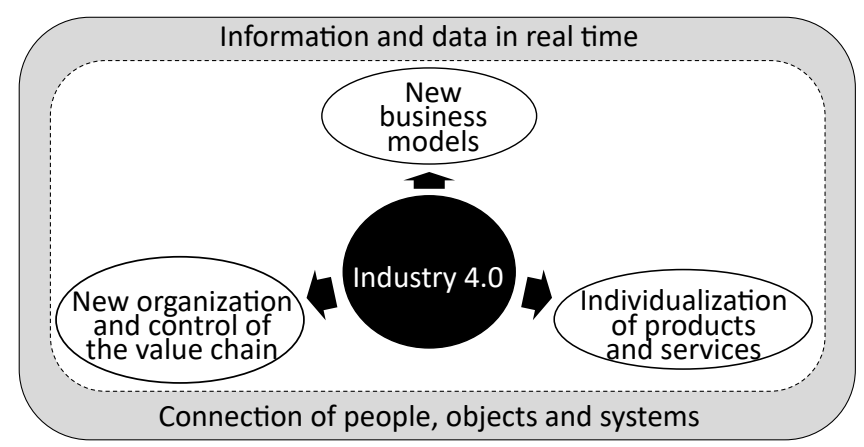

Figure 1. Industry 4.0 overview. Source: Landherr et al. (2016).

For the implementation of the Smart Factory concept, it is necessary to use technologies consisting of simulation and modeling systems for data processing as well as digitalization and virtualization tools. All of these ought to work synchronously for integration between the real and the virtual environments.

Anderl (2014) states that the fundamental aspect of Industry 4.0 refers to using the ability of the cyber-physical systems to provide intelligence and communication for technical systems, which assume this configuration to be called intelligent systems. Xu et al. (2018) highlight that Industry 4.0 emphasizes the search for fully integrated solutions dedicated to the operation of digital manufacturing systems. 
Some key concepts and technologies related to the Industry 4.0 environment were listed by Oesterreich and Teuteberg (2016). As a result, they present 15 concepts/technologies grouped into three groups (Smart Factory, Simulation and Modelling, and Digitalization and Virtualization), as shown in Table 1.

Table 1. Key technologies and concepts in the context of Industry 4.0 .

\begin{tabular}{|c|c|}
\hline Group & Technologies and concepts \\
\hline \multirow{8}{*}{ Smart Factory } & $\begin{array}{l}\text { Cyber-Physical Systems (CPS) } \\
\text { Embedded Systems } \\
\text { Radio-Frequency Identification (RFID) }\end{array}$ \\
\hline & $\begin{array}{c}\text { Internet of Things (IoT) } \\
\text { Internet of Services (IoS) }\end{array}$ \\
\hline & Automation \\
\hline & Modularization \\
\hline & Additive Manufacturing \\
\hline & Product Lifecycle Management (PLM) \\
\hline & Robotics \\
\hline & Human-Computer Interaction $(\mathrm{HCl})$ \\
\hline \multirow[b]{2}{*}{$\begin{array}{l}\text { Simulation } \\
\text { and modeling }\end{array}$} & Simulation tools and models \\
\hline & $\begin{array}{l}\text { Augmented Reality (AR) } \\
\text { Virtual Reality (VR) } \\
\text { Mixed Reality (MR) } \\
\end{array}$ \\
\hline \multirow{5}{*}{$\begin{array}{l}\text { Digitalization and } \\
\text { virtualization }\end{array}$} & Cloud Computing \\
\hline & Big Data \\
\hline & Mobile Computing \\
\hline & Social Media \\
\hline & Digitalization \\
\hline
\end{tabular}

Source: Oesterreich and Teuteberg (2016).

The information presented in this article portrays a general overview of Industry 4.0, addressing more directly the areas of Smart Factory, Digitalization and Virtualization, Simulation and Modeling. The above definition can guide the direction of research on Industry 4.0 and improves the visualization of the scenario based on the terms present in the literature.

Some authors indicate the technological factors that are essential to enable the configuration of Industry 4.0, the following are among them: Cyber-Physical Systems (CPS), Internet of Things (IoT), Big Data, and Cloud Computing (Kagermann et al., 2013; Oesterreich et Teuteberg, 2016; Xu et al., 2018; Zhong et al., 2017). These concepts and technologies are central features to this study.

\section{Key definitions}

\section{Cyber-Physical Systems (CPS)}

Cyber-Physical Systems are the fundamental concept for the operation of Industry 4.0 because their operation depends on the integration between physical components and computational algorithms (Xu et al., 2018). In this way, CPS promotes integration between virtual and physical environments.

Cyber-Physical systems are computer, network, and physical process integrations, where networked systems monitor and control physical processes; these return production data to provide real-time information exchange. Kagermann et al. (2013) also define the cyber-physical systems as a set consisting of intelligent machines, storage systems, and production facilities capable of exchanging information, triggering actions and controls autonomously and harmoniously. This operation occurs in real time in the Intelligent Factory environment.

Among the many expectations generated for the operation of CPS are: safety, robustness at every level, self-organization, self-maintenance, self-repair, remote diagnosis, efficiency, real-time control, autonomous navigation, predictability, efficiency, and model correctness (Monostori et al., 2016). However, this author emphasizes that having expectation in so many aspects can be considered inappropriate.

Oesterreich et Teuteberg (2016) mention that CPS is composed of key technologies such as: Product Lifecycle Management (PLM), Modularization and Robotics, Mobile Computing, and Radio Frequency Identification (RFID), but not limited solely to those. In summary, cyber-physical systems are a key structure for the operation of the Smart Factory; therefore, without this concept it would be impossible to develop Industry 4.0.

\section{Internet of Things (IoT)}

Internet of Things (IOT) is one of the biggest development trends in the communication technology segment (Miorandi et al., 2012). loT enables physical devices to network to exchange information/data between different levels of hierarchy.

Van Kranenburg (2008) mentions that loT is a dynamic network that has ability to configure itself according to the communication protocols. In loT configuration, physical and virtual "things" have identity, attributes, and personality; they also use intelligent interfaces that integrate the information network, highlighting the use of radio-frequency identification (RFID) and wireless sensor networks (WSN) (Xu et al., 2018).

According to Oesterreich et Teuteberg (2016), among the benefits that loT technology can generate is the ability of the equipment to send performance data to be analyzed by the engineering group, contributing to the strategy of the digital 
integration of engineering with the value chain. Additionally, it helps the company obtain the complete Big Data from the product supply chain, which leads to improvements such as more efficient storage and distribution planning, and consequently cost savings (Cao et Zhang, 2016).

However, Zdravković et al. (2017) highlight that one of the challenges for deploying loT networks is the lack of public policies and regulatory measures.

\section{Big Data}

Big Data is an innovation in the Information Technology area that makes it possible to make optimized simulations of data in real time, saving time and costs as well as reducing risk in decision-making (Kagermann et al., 2013).

According to Lee et al. (2015), Big Data basically consists of a large amount of data that is generated by the use of sensors and networked machines. This structure enables the adequate collection of data of different types and originating from different sources, for example, sensors, computers, IT systems, machines, and people. It also provides access to the history of information generated by the entire integrated value chain.

The benefits of using a Big Data platform in the industrial environment include: improving data mining capacity, collecting large amounts of information from different devices, improving the ability to process data from the company's information system, in addition to achieving real-time analysis of product data, operating data, sales data, and customer data (Cao and Zhang, 2016).

Big Data is considered a challenge for the implementation of industry 4.0 because it consists of a set of data collected from different sources (from the machines sensors, from quality, logistics, and others), therefore requiring a huge infrastructure to store, process, and manage all the information.

In addition, the lack of standardization in data management is a barrier to operationalization, since the current industry environment has heterogeneous information (Khan and Turowski, 2016). Finally, efforts should be directed to the improvement of the knowledge on how to acquire, use, and interpret more effectively the real value that all these collected data generate, thus helping in decision-making.

\section{Cloud Computing}

Cloud Computing enables access to computing resources (servers, storage, and operating systems) in a shared way where it can be configured and delivered on demand (Ardolino et al., 2017). The cloud computing architecture can be generally divided into layers: hardware/datacenter layer (infrastructure as a service), infrastructure layer (infrastructure as a service), platform layer (platform as a service), and application layer (software as a service) (Zhang et al., 2010).

In this context, companies can store their data on private or public servers, and the execution of complex tasks can be supported by the use of cloud computing (Xu et al., 2018). Monostori et al. (2016) mention that one of the most promising applications of cloud computing in the industrial environment is to support the acquisition, distribution, and use of information from machines and processes across spatial boundaries.

Cloud computing contributes to the flexibility of the industry, as it allows the storage, processing, and analysis of data. Moreover, the information is updated and made available in real time and can be accessed from anywhere, provided internet access is available.

In general, cloud computing is one of the technologies that can support the effective decision-making process. Despite its many benefits, cloud computing is still not a mature technology and presents a few challenges, including automatic provision of resources, energy management, and security (Zhang et al., 2010).

\section{Strategic and operational aspects}

In order to allow a gradual transition from current production systems to an intelligent factory structure, actions must be driven at the level of company management, as they translate the company's strategy and guide implementation processes. At the operational level, they also define the applicable technical concepts and technologies.

Xu et al. (2018) mention that in the context of Industry 4.0 , the concept of business process management is still an undervalued subject, and they identify the need to promote studies to integrate the models into a standard structure. According to Müller et al. (2018), from a strategic perspective, the business models of Industry 4.0 generate economic benefits because they positively influence the competitiveness of the company.

The operational aspects refer to the systems and technical resources necessary for an intelligent factory environment, among which one can mention Cyber-Physical Systems, Internet of Things, and Big Data. This structure is composed of sensors, components, machines, controllers, networks, computational algorithms, software, and hardware. 
Lee et al. (2015) present operational architecture into levels: Smart Connection, Data-to-Information Conversion, $\mathrm{Cy}$ ber, Cognition, and Configuration. The operational perspective also generates economic benefits due to factors such as the availability of real-time data across the whole supply chain and manufacturing quality (Müller et al., 2018).

\section{RESEARCH CLASSIFICATION}

This study assumes an exploratory character because the subject of study is still in the knowledge-structuring phase. In this sense, the object of study, the context of Industry 4.0, was basically investigated through a literature review.

The literature review was conducted in a qualitative and organized way in two main stages. Firstly, the main definitions regarding Industry 4.0 were researched in order for a superior understanding of this environment's operation to be achieved, allowing the construction of a proposal for implementation stages. Secondly, the research was conducted in a more targeted way to detail the stages of the implementation proposal.

The literature review used material from academic sources collected from four databases: Engineering Village - COMPENDEX, Emerald, Web of Science, and Taylor \& Francis. Furthermore, some reports and websites of renowned consultancies were consulted.

This procedure of data collection enabled an analysis of different points of view of several authors and provided the identification of motivations for the development of the study in the field of Industry 4.0, contributing to the construction of knowledge and science. The synthesis of the research classification is presented in Figure 2.

\section{METHODOLOGY FOR INDUSTRY 4.0 IMPLEMENTATION}

This study presents a conceptual proposal for the Industry 4.0 implementation structure that is organized in steps covering the strategic and operational points of view during the flow.

In addition, this research intends to present a way for companies to introduce the aspects of Industry 4.0 to their own benefit, although this is still in the structuring phase.

The proposed methodology was based on the study promoted by the PWC (2016), which discussed strategic drivers for digital success. In addition, new approaches have been inserted from other literature sources.

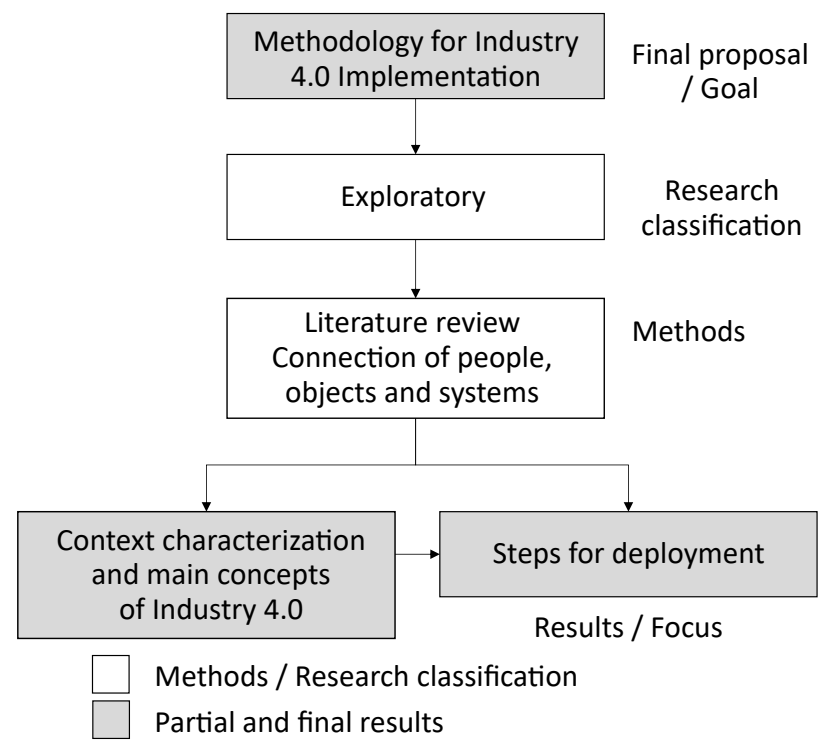

Figure 2. Research classification. Source: The authors.

Figure 3 presents the flowchart of the proposed methodology, which is structured in six steps that will be described, based on a literature review, and related during this section.

\section{Strategy mapping}

The first stage consists of strategy mapping, in which the company must make a self-assessment to basically analyze the level of maturity, to reflect on the challenges and barriers, and finally to define the goal that it wants to achieve.

To evaluate the level of maturity of a company, support tools are recommended. In the literature, some models discuss how to measure maturity in the field of Industry 4.0, for example the proposal presented by Schumacher et al. (2016), which shows the evaluation of the dimension by means of the calculation of an indicator, obtained with the analysis of nine dimensions structured in 62 items.

However, in this study, a qualitative matrix is adopted as support for measuring maturity level. This matrix is organized in four stages of development and seven dimensions, helping to diagnose the level of the company and vision of the next stages (PWC, 2016). Figure 4 shows the scheme of this maturity assessment model.

In the maturity matrix, the stages of Digital beginner and Vertical integrator are more related to the internal environment of the company. The level of Horizontal collaborator and Advanced digital stages apply to the external environment in which there is an external relationship with the network of partners and customers belonging to the supply chain. 


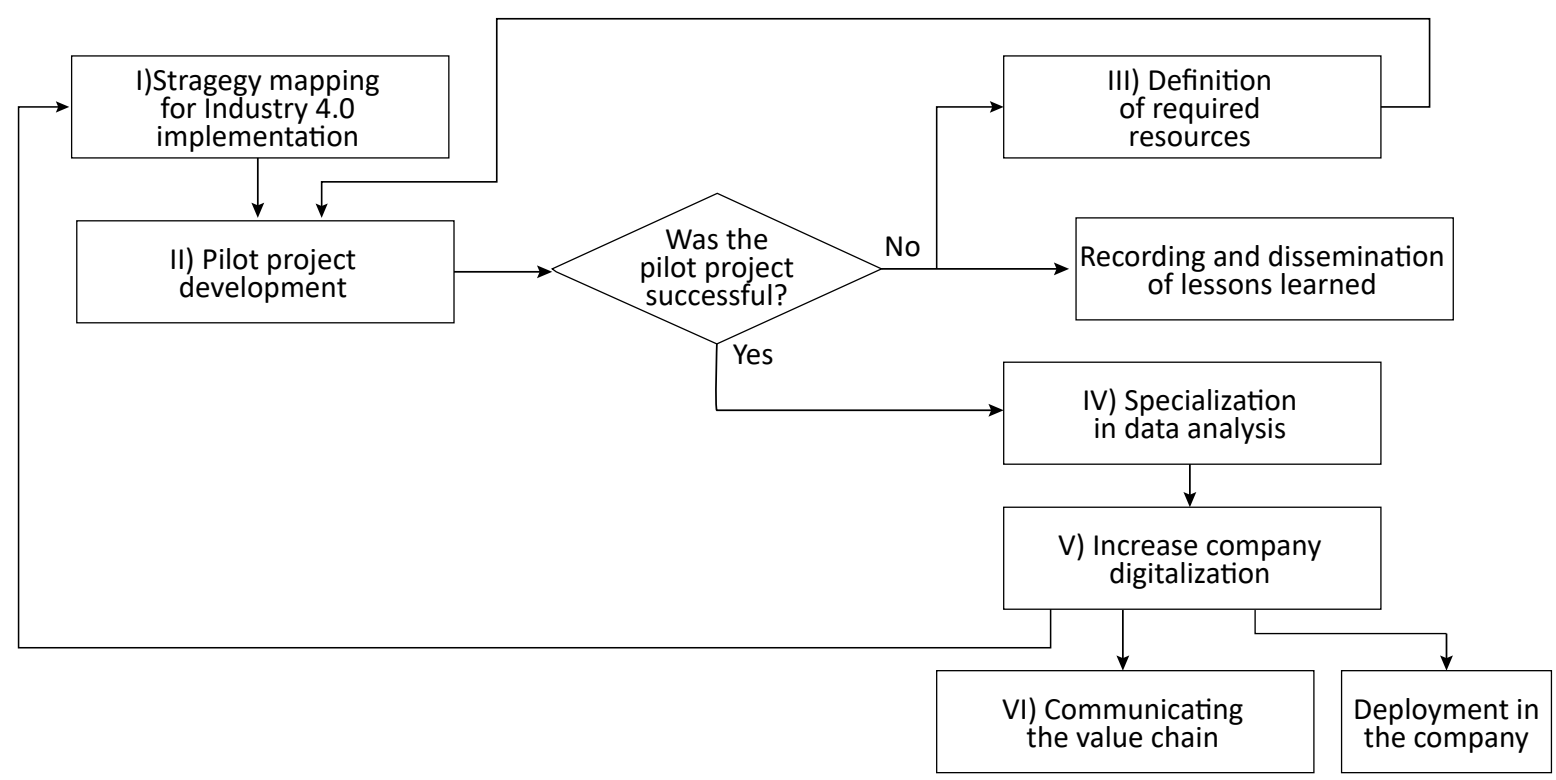

Figure 3. Steps for Industry 4.0 implementation.

Source: The authors.

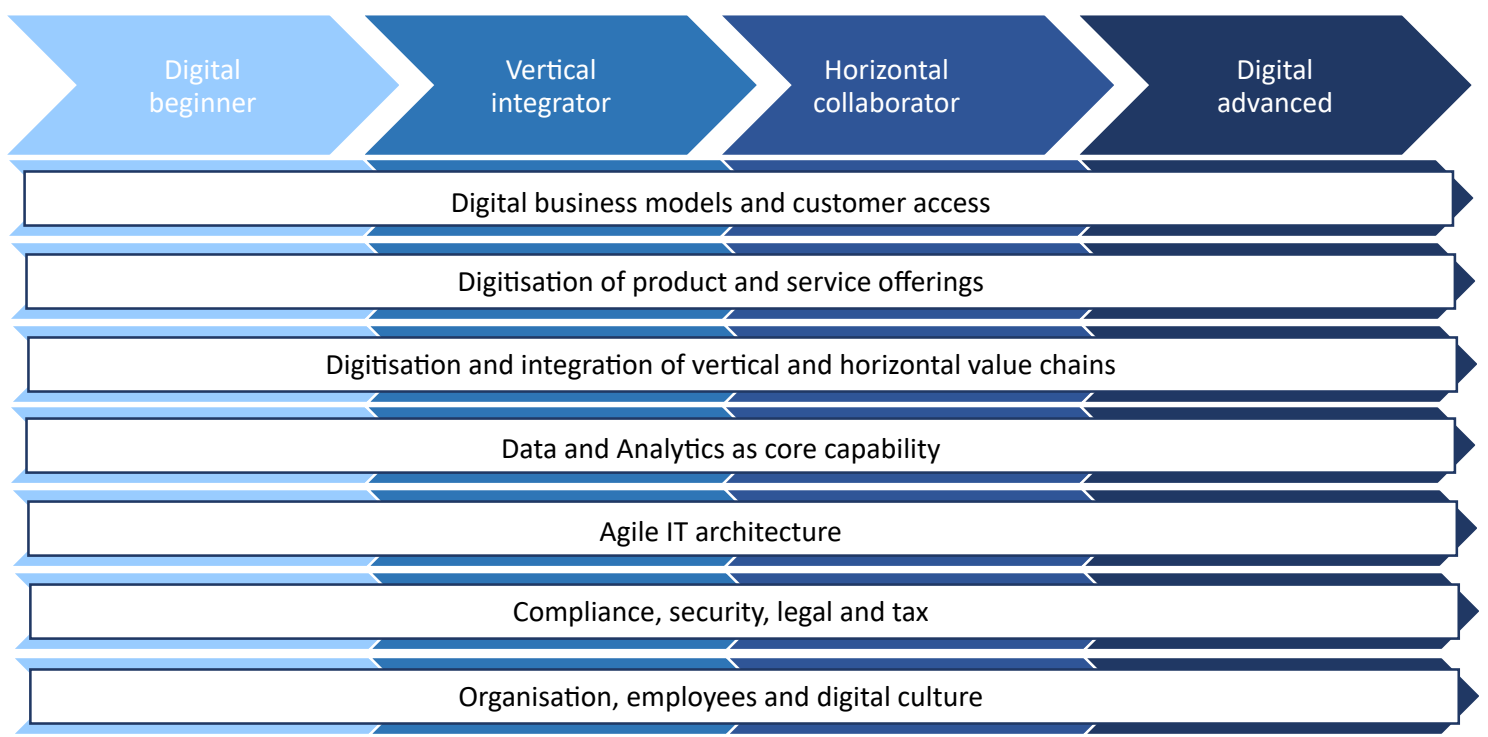

Figure 4. Overview of enterprise maturity assessment model for Industry 4.0 development.

Source: Adapted from PWC (2016).

Additionally, there are some cases in which the company cannot fully develop the seven dimensions at the same stage of development. Nonetheless, it is important to properly assess the real level of maturity that represents the current company scenario.
After analyzing the maturity level, it is also necessary to verify the presence of the main barriers and challenges for the implementation of the Industry 4.0 environment as well as to have its definitions clarified. For this purpose, Table 2 presents a summary of the main aspects that should be considered based on the literature. 
Table 2. Barriers and challenges for the implementation of the Industry 4.0.

\begin{tabular}{|c|c|c|}
\hline $\begin{array}{l}\text { Obstacles/ } \\
\text { Challenges }\end{array}$ & Description & Authors \\
\hline High investment & $\begin{array}{l}\text { New technological profiles will require large investments in infrastructure } \\
\text { and capacity building. }\end{array}$ & Oesterreich and Teuteberg (2016) \\
\hline $\begin{array}{l}\text { Obstacles/ } \\
\text { Challenges }\end{array}$ & Description & Authors \\
\hline $\begin{array}{l}\text { New professional } \\
\text { profile }\end{array}$ & $\begin{array}{c}\text { Demand for a new professional profile with more specific and/or technical } \\
\text { knowledge about the operation of the new intelligent manufacturing model. } \\
\text { On the company's side, it is necessary to implement training strategies and } \\
\text { promote a culture of sharing of good practices. }\end{array}$ & $\begin{array}{l}\text { Oesterreich and Teuteberg (2016); } \\
\text { Prause and Weigand (2016); Khan } \\
\text { and Turowski (2016); Kagermann et } \\
\text { al. (2013) }\end{array}$ \\
\hline $\begin{array}{l}\text { Employee } \\
\text { engagement }\end{array}$ & $\begin{array}{l}\text { Resistance to change and fear of exchanging people for smart equipment. } \\
\text { Difficulty in accepting tecnology and associated knowledge. }\end{array}$ & $\begin{array}{l}\text { Oesterreich and Teuteberg (2016); } \\
\text { Khan and Turowski (2016); } \\
\text { Kagermann et al. (2013) }\end{array}$ \\
\hline $\begin{array}{l}\text { Lack of standard- } \\
\text { ization and refer- } \\
\text { ence architectures }\end{array}$ & $\begin{array}{l}\text { Concepts are still under construction. Model proposals should cover } \\
\text { a strategic level and the standardization of technical aspects } \\
\text { with the aim of facilitating implementation. }\end{array}$ & $\begin{array}{l}\text { Oesterreich and Teuteberg (2016); } \\
\text { Khan and Turowski (2016); } \\
\text { Kagermann et al. (2013) }\end{array}$ \\
\hline Safety & $\begin{array}{l}\text { The data security is a risk factor, due to it involving a dynamic process of } \\
\text { sharing, collaboration, mobility, large volumes of data, and various sources. }\end{array}$ & $\begin{array}{l}\text { Oesterreich and Teuteberg (2016); } \\
\text { Khan and Turowski (2016); } \\
\text { Kagermann et al. (2013) }\end{array}$ \\
\hline $\begin{array}{l}\text { Communication } \\
\text { networks }\end{array}$ & $\begin{array}{l}\text { There must be an effective connectivity infrastructure available that allows } \\
\text { access and sharing of data through a quality internet network, thereby, } \\
\text { ensuring real-time data flow and process integration. }\end{array}$ & $\begin{array}{l}\text { Oesterreich and Teuteberg (2016); } \\
\text { Khan and Turowski (2016); } \\
\text { Kagermann et al. (2013) }\end{array}$ \\
\hline $\begin{array}{l}\text { Organizational } \\
\text { and Process } \\
\text { Changes }\end{array}$ & $\begin{array}{l}\text { A new work organization will be required to support production } \\
\text { with mass customization. } \\
\text { There will be a need for a collaborative working environment } \\
\text { and continuous use of knowledge management for this intelligent } \\
\text { manufacturing structure to be fully established. }\end{array}$ & $\begin{array}{l}\text { Oesterreich and Teuteberg (2016); } \\
\text { Khan and Turowski (2016); } \\
\text { Brettel et al. (2014); } \\
\text { Kagermann et al. (2013) }\end{array}$ \\
\hline $\begin{array}{l}\text { Legislation / } \\
\text { Regulations }\end{array}$ & $\begin{array}{c}\text { Need to develop specific legislation for these technological innovations. } \\
\text { Particular attention should be paid to issues of corporate } \\
\text { data protection and accountability. }\end{array}$ & $\begin{array}{l}\text { Oesterreich and Teuteberg (2016); } \\
\text { Kagermann et al. (2013) }\end{array}$ \\
\hline Data processing & $\begin{array}{c}\text { The systems involved in Industry } 4.0 \text { will generate an enormous amount } \\
\text { of data from diverse sources, demanding a huge capacity of storage, } \\
\text { processing, and management. }\end{array}$ & Khan and Turowski (2016) \\
\hline Technology & $\begin{array}{c}\text { The various concepts of Industry } 4.0 \text { did not evolve in a balanced way; } \\
\text { as a result, they are currently at different levels of maturity, } \\
\text { and some of these are still at the early stages of modeling. }\end{array}$ & $\begin{array}{l}\text { Oesterreich and Teuteberg (2016), } \\
\text { Khan and Turowski (2016) }\end{array}$ \\
\hline
\end{tabular}
Source: The authors.

The set of barriers and challenges for the deployment of Industry 4.0 should be regarded as a checklist of important points the definition and existence of which the company and its team need to consider.

After identifying the company's current stage of maturity and detailing the challenges and barriers to be faced, the team must then clearly define the objective of the implementation of the Industry 4.0 project.

The objective of the project should be composed of realistic goals, considering the points raised and the definition of the maturity level that the company intends to reach after implementation. Therefore, the next step can be initiated.

\section{Pilot project development}

The second step is the development of a pilot project in the production system. The execution of a pilot project is a better way to provide solid foundation for the industrial transformation and upgrading (Feng et al., 2018). This step transforms the approaches of strategy mapping into concrete and practical projects, which are based on the company's initial maturity evaluation and in the objectives and goals defined at the first stage.

The planning of this stage is intended to be carried out based on project management concepts. In this way, it is possible to define and manage the scope of the project, allowing the implementation to follow a guideline aligned 
Brazilian Journal of Operations \& Production Management

Volume 16, Número 2, 2019, pp. 166-179

DOI: 10.14488/BJOPM.2019.v16.n2.a1 with the company's strategic planning, the project teamwith all members' requirements and responsibilities-, and the project costs. Considering the risks inherent to the project is also possible.

In addition, applying project management knowledge helps to increase the chances of successful execution of an activity of this nature (projects in the context of Industry 4.0) which has several risk factors. Indeed, the uncertainty about costs and impact of projects about new technologies can influence companies (Schumacher et al., 2016).

Another important contribution is that the lessons learned should be evaluated, documented, and disseminated at the project end. In this case of Industry 4.0, regarding pilot projects that directly involve technological innovations, the knowledge generated from lessons learned can neither be retained nor lost. It is thus necessary to disclose and store the information. Project teams can be facilitators of knowledge sourcing and reuse, which is critical for innovations (Shamim et al., 2016).

Tupa et al. (2017) point out that the concept of Industry 4.0 generates new types of risks, mainly due to increased vulnerability and threats. Among the risks in this area are: data loss, information unavailability, problems with availability and data integrity for maintenance, data processing error, cyber-attacks, low quantity of skilled labor, problems with compatibility, and electromagnetic emissions that affect the machines in the productive process.
After the project planning, the pilot project must be started. For this purpose, in order to direct the development of the operational aspects, Lee et al. (2015) is referred to in this study, which presents an architecture structure that can support the execution of these projects. This architecture, illustrated in Figure 5, demonstrates the five levels of evolution of the production system in conjunction with the attributes required for the Industry 4.0 configuration.

Considering the operating systems architecture, it is noticed that Smart Connection, considered the first level of implementation of a Cyber-Physical System, focuses on the development of hardware installation that allows data collection from the production system in real time, for example, with the use of sensors (Lee et al., 2015).

The Data-to-Information Conversion Level allows the access to information of the large volume of data collected, for example, knowledge about the useful life of the machines and their performance (Lee et al., 2015; Qin et al., 2016). In this case, the sensors that monitor temperature, vibrations, noise or wear are crucial (D'Antonio et al., 2015; Vachálek et al., 2017).

At Cyber Level, there is control of the entire network, thus the machines gain the ability to self-evaluate, in addition to comparing current yields with other machines. This is possible due to the existence of a physical and digital model for the same equipment (Lee et al., 2015; Schluse et al., 2018).

\section{FUNCTIONS}

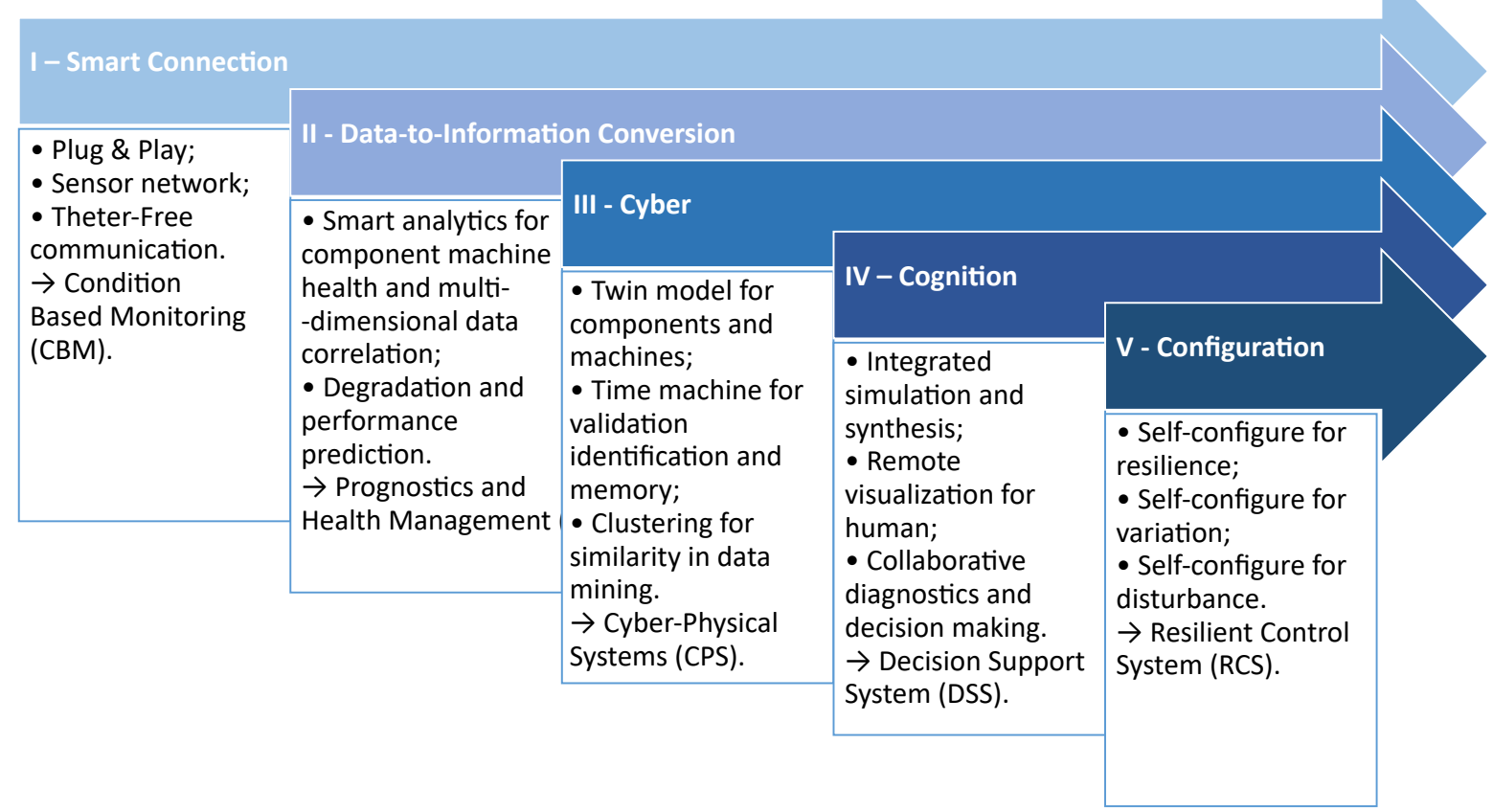

Figure 5. Architecture for manufacturing in the context of Industry 4.0. 
Finally, at the Cognition Level and Configuration Level the necessity of artificial intelligence is identifiable. At the Cognition Level, the system is integrated, and decisions are made through graphs that contemplate the entire production system and all process variables. Comparative graphs are generated as well as individual equipment graphs and prioritization decisions to optimize the process. However, decisions are still made by users (Isaksson et al., 2018; Uhlemann et al., 2017).

At the Configuration Level, the system sets itself up and decision-making happens without human intervention. This step acts as a Resilience Control System (RCS) to apply corrective and preventive decisions based on decisions taken at the Cognition Level (Lee et al., 2015).

In general, the pilot project can be developed at different levels considering the architecture presented, which will depend on the of the company's degree of maturity. Finally, pilot projects can contribute in two ways. If these are successful, they can enter the company, starting with Specialization in data analysis. Therefore, there will be no loss of the initial investment made. However, if they do not have satisfactory results, an analysis of the possible reasons is paramount; moreover, there is value in learning about the organization itself. In this case, it is recommended that the Definition of required resources step be performed.

\section{Definition of required resources}

Based on pilot projects that were unsuccessful, it is imperative that an analysis of the capabilities needed for development be carried out. Here, the definition of capabilities is not limited only to physical resources (e.g. sensor network, data exchange enabled machines); it also relates to human resources (e.g. need for a knowledge in data mining). In the Human Resources area, this new environment will demand a new profile of professionals with new skills; therefore, the approach between the industry and university is a decisive strategy for qualification of current and future workers (Mancilha and Gomes, 2018).

In this direction, the concept of digital compass, developed by McKinsey \& Company (2015), and illustrated in Figure 6 , can be utilized as a guide.

The digital compass consists of eight values and assists the company by providing information on the direction in which each capacity needs to be improved. Moeuf et al. (2018) cite in their study an example directly related to the issue of the development of skills related to inventories, more specifically for real time supply chain optimization. The application consists of the use of algorithms for optimization of production planning, in which the production data in real time is used to modify the production plan through changes in demand or interruptions in the process (Moeuf et al., 2018; Peng et al., 2012).

\section{Specialization in data analysis}

After the successful implementation of the initial pilot project, the data analysis improvement phase begins. This stage generally consists of organizing and analyzing the data generated more adequately in order to improve the decision-making process. This stage involves the structuring of systems that allow the combination of different data and the training of the team to develop these skills.

It is noteworthy that from a certain level of development of Industry 4.0, the decision-making is done by the system itself, that is, automated event handling with database support and algorithms. In this structure, one can benefit from the use of artificial intelligence that simulates the thought process in conjunction with the application of data mining, which extracts from a massive amount of data the useful information that triggers reconfiguration actions (Cheng et al., 2018).

Thus, the process of training in data analysis is a major challenge since the structure of Industry 4.0 is a complex system that involves several technologies. Therefore, there should be a direction for professional development in a continuous way based on the place of work and with initiatives that promote learning (Liao et al., 2017).

\section{Increase company's digitalization}

At this stage, an expansion of the company's digitalization is proposed. In order to capture the benefits of Industry 4.0 , it is often valuable to make the entire enterprise digital, namely, evolve to the level of maturity of Digital advanced, as shown in Figure 4.

Based on the pilot project carried out at the second stage, and on the specifications of requirements and analyses, the total digitalization of the production system must be sought.

For this to be achieved, the expansion of data collection capacity, management, and analysis for the entire plant is essential (Armengaud et al., 2017; Bloching et al., 2015). This data collection must be carried out in real time, which is the reason for highlighting the MES (Manufacturing Execution Systems) and RFID tools (Efendioglu and Woitsch, 2017; Ferro et al., 2017; Uhlemann et al., 2017).

Another factor to consider in this step is the ability of the digital model to connect with the rest of the supply chain 


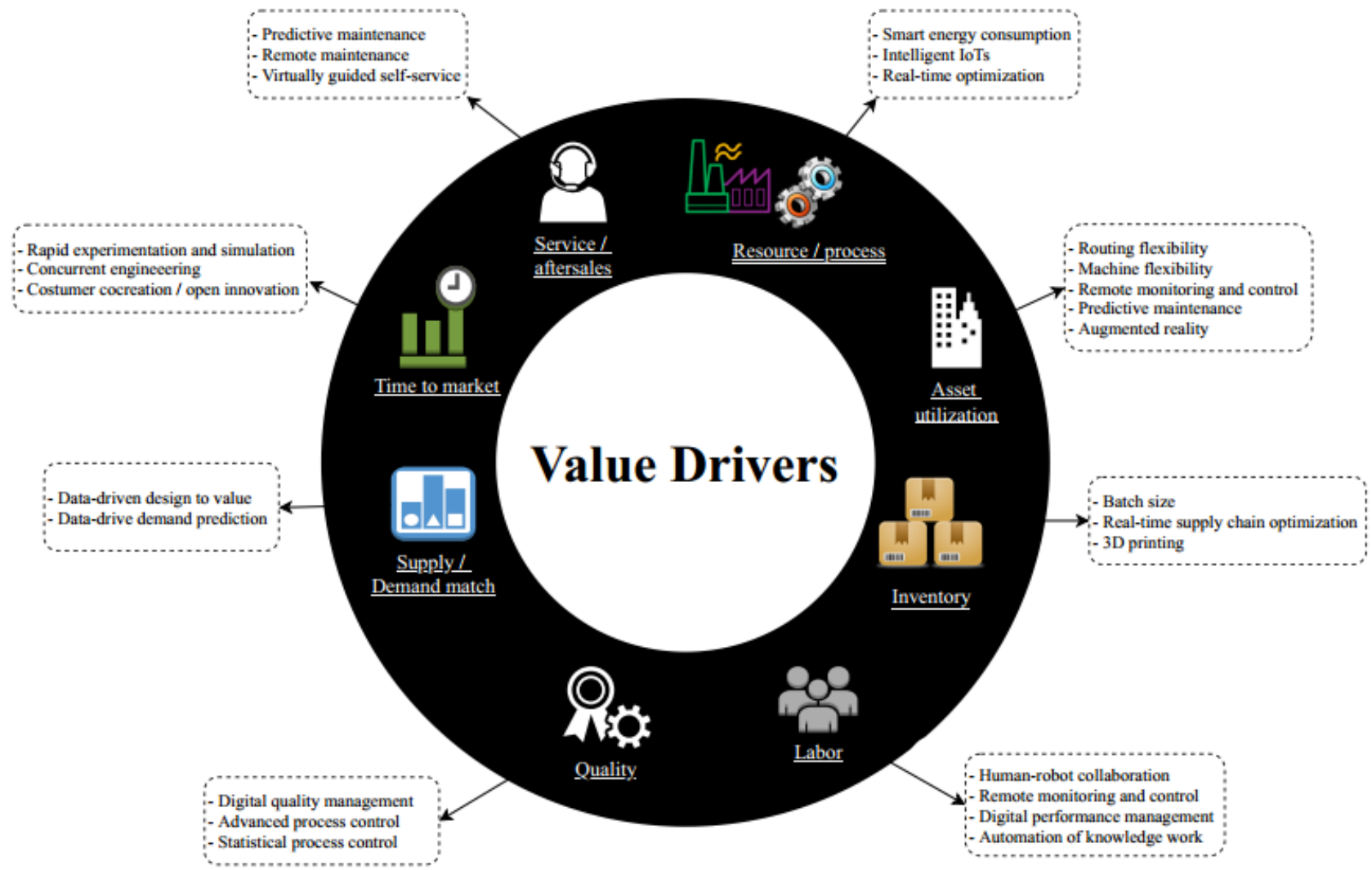

Figure 6. Digital compass for capacity building.

Source: McKinsey \& Company (2015).

and customer needs (Isaksson et al., 2018). In this regard, the twin factory concept will be applied to the entire production system, allowing the simulation of new scenarios and the optimization of the production system to be performed in the digital environment without intervention in the real environment.

\section{Communicate the value chain}

After the implementation of the company's digitalization projects, it is necessary to expand this process or concept to the whole value chain. That involves communicating the process from the extraction of the inputs to the distribution to the final customer, thus improving flexibility and agility in the decision-making process.

Mazak and Huemer (2015) mention that the value chain analyzes all the functions of the company's business and establishes how this structure is related. By aligning the levels of development and application of the Industry 4.0 structure among a network of partner companies, it is possible to reach a digital value chain structure.

It should be noted that the availability of real-time data and interconnected systems contributes to companies align- ing their processes with each other and forming a more flexible structure, which expands the connected supply chain concept (Montanus, 2016).

Hofmann and Rüsch (2017) describe that in the digital dimension of the value chain data is collected from the physical environment throughout the supply chain; afterwards, by using a connectivity layer, these data are made available for analysis. The same authors point out that in this structure there are components of customer value such as value of availability, which is one of the main values delivered in a logistics and service structure, value of digital integration refers to traceability along the chain of supplies, and finally, the final value created by consumption that exceeds the standard sales projection.

An integrated digital value chain structure relies on key aspects such as cyber-physical systems and Product Lifecycle Management, which can not only allow the integration of processes in the internal environment of a company, but also allow interaction with the external environment (Oesterreich and Teuteberg, 2016).

Strategic alignment across the value chain to fit the context of Industry 4.0 is possible through the establishment of partnerships. However, companies should be willing to make 
investments as well as share data and information, such as data on stock levels. In situations where cooperation is not possible, one can even think of alternatives such as mergers or acquisitions.

\section{Summary of steps flow}

This section provides an overview of the flow of the proposed methodology for implementing the Industry 4.0 concept in modern companies.

This study's proposal is composed of six stages, beginning with stage I) Strategy mapping, considered the starting point for the whole process. At this stage, the main objective is to understand the company context and the project implementation proposals for the implementation of the concepts of Industry 4.0. It is worth mentioning that this activity has a specifically management nature.

Stage II) Pilot project development is done with the purpose of implementing in a small scale what was defined from the strategic mapping. From the results of the pilot projects in stage II, it is possible to define the path for the effective implementation of what was planned. If it not approved, the sequence progresses to step III) Definition of required resources, which consists of analyzing the situation and developing the respective demanded capacities. With the problems and difficulties solved, one can return to step II to remake the pilot projects.

In cases where the pilot project has been successful, the path from stage II is directed to IV) Specialization in data analysis, where the physical structure is improved as human resources. Subsequently, stage V) Increase company digitalization, refers to follow-up of the deployed project and evolution of the company's digital maturity level.

With the improved digitalization of the deployed company, it is recommended to communicate the entire value chain, stage VI, as well as to provide information for stage I to develop new strategies that will provide continuity to the stages of development of Industry 4.0, which were traced in the maturity model.

Finally, it is important to clarify that implementing the concept of Industry 4.0, through the structuring of projects or other initiatives, requires the effective involvement of top management that identifies the true value created by this structure for the company business. From this information, programs can be promoted aimed at changes, both in organizational structure and production (Müller et al., 2018).

\section{FINAL REMARKS}

The structuring and implementation of the context of Industry 4.0 is currently undergoes a process of evolution and presents to companies the trend of a new format of business model. Essentially, the Industry 4.0 environment has a high degree of technological development and collaborative structure, which is characterized mainly by the communication between different agents (hardware, software, data, people), allowing the exchange, storage, and interpretation of data in an intelligent system.

Considering that, this study presented an investigation of the central concepts that involve the theme as well as a theoretical proposal of implementation organized in six stages, which considers the strategic and operational aspects. In this way, it is oriented to support and encourage the adoption of technologies and concepts indicated by the literature on Industry 4.0 .

However, it should be noted that the emergence and introduction of new technologies in the manufacturing process and in the companies' structures as a whole always presents significant risks initially-until knowledge is consolidated and experience can be obtained in the area. Therefore, it is worth mentioning that the proposal here introduced represents an initial investigation of implementation procedures and can be adapted to specific contexts, depending on the need.

\section{Research limitations and future perspectives}

The limitations of this study are directly related to its theoretical nature and the difficulty of finding tools that help in the execution of each proposed stage. In addition, based on theoretical insights, a trajectory of a transformation model is proposed, which still needs to be validated in practice, allowing the level of acceptability of people and adherence to a real scenario.

Nevertheless, despite its limitations, this proposal's application potential is noticeable. Thus, the recommendations for future work consist of: (a) Promoting detailed scientific studies on each stage described, mainly investigating a tool for quantitative measurement for maturity analysis in this context of Industry 4.0; (b) Testing the proposed structure in a real project; (c) Developing a project prototype of the Industry 4.0 environment.

\section{REFERENCES}

Anderl, R. (2014), "Industrie 4.0 - Advanced Engineering of Smart Products and Smart Production", 19 Seminário Internacional de Alta Tecnologia - Inovações Tecnológicas no Desenvolvimento do Produto, pp. 3-16. 
Brazilian Journal of Operations \& Production Management Volume 16, Número 2, 2019, pp. 166-179

DOI: 10.14488/BJOPM.2019.v16.n2.a1
Ardolino, M.; Rapaccini, M.; Saccani, N. et al. (2017), "The role of digital technologies for the service transformation of industrial companies", International Journal of Production Research, Taylor \& Francis, Vol. 7543, pp. 1-17.

Armengaud, E.; Sams, C.; von Falck, G. et al. (2017), "Industry 4.0 as digitalization over the entire product lifecycle: Opportunities in the automotive domain", In Systems, Software and Services Process Improvement - 24th European Conference, EuroSPI 2017, Proceedings, Vol. 748, pp. 334-351.

Bloching, B.; Leutiger, P.; Oltmanns, T. et al. (2015), "The Digital Transformation of Industry", Roland Berger Strategy Consultants $\mathrm{GmbH} \& \mathrm{BDI}$, p. 52.

Brettel, M.; Friederichsen, N.; Keller, M. et al. (2014), “How Virtualization, Decentrazliation and Network Building Change the Manufacturing Landscape: An Industry 4.0 Perspective", International Journal of Mechanical, Aerospace, Industrial, Mechatronic and Manufacturing Engineering, Vol. 8, No. 1, pp. 37-44.

Cao, J.; Zhang, S. (2016), "The Application and Design of Big Data in Operation and Maintenance of Industry 4.0", 6th International Conference on Machinery, Materials, Environment, Biotechnology and Computer (MMEBC 2016), Atlantis Press, pp. 1845-1850.

Cheng, Y.; Chen, K.; Sun, H. et al. (2018), "Data and knowledge mining with big data towards smart production", Journal of Industrial Information Integration, Vol. 9 No. August 2017, pp. 1-13.

D'Antonio, G.; Bedolla, J. S.; Genta, G. et al. (2015), “PLM-MES Integration: A Case-Study in Automotive Manufacturing", IFIP Advances in Information and Communication Technology, Vol. 467, pp. 780-789.

Efendioglu, N.; Woitsch, R. (2017), "Serviceology for Services 5th International Conference, ICServ 2017 Vienna, Austria, July 12-14, 2017 Proceedings", Vol. 10371, pp. 153-163.

Feng, L.; Zhang, X.; Zhou, K. (2018), "Current problems in China's manufacturing and countermeasures for industry 4.0", EURASIP Journal on Wireless Communications and Networking, EURASIP Journal on Wireless Communications and Networking, Vol. 2018, No. 1, p. 90.

Ferro, R.; Ordóñez, R. E. C.; Anholon, R. (2017), “Analysis of the integration between operations management manufacturing tools with discrete event simulation", Production Engineering, Vol. 11, No. 4-5, pp. 467-476.

Hofmann, E.; Rüsch, M. (2017), "Industry 4.0 and the current status as well as future prospects on logistics", Computers in Industry, Elsevier B.V., Vol. 89, pp. 23-34.

Isaksson, A. J.; Harjunkoski, I.; Sand, G. (2018), "The impact of digitalization on the future of control and operations", Computers and Chemical Engineering, Elsevier Ltd, Vol. 114, pp. 122-129.
Kagermann, H.; Wahlster, W.; Helbig, J. (2013), "Recommendations for implementing the strategic initiative INDUSTRIE 4.0", Final Report of the Industrie 4.0 WG, No. April, p. 82.

Kamble, S. S.; Gunasekaran, A.; Gawankar, S. A. (2018), "Sustainable Industry 4.0 framework : A systematic literature review identifying the current trends and future perspectives", Process Safety and Environmental Protection, Institution of Chemical Engineers, Vol. 117, pp. 408-425.

Khan, A.; Turowski, K. (2016), "A Perspective on Industry 4.0: From Challenges to Opportunities in Production Systems", pp. 441-448.

Landherr, M.; Schneider, U.; Bauernhansl, T. (2016), "The Application Center Industrie 4.0 - Industry-driven Manufacturing, Research and Development", Procedia CIRP, Elsevier B. V., Vol. 57, pp. 26-31.

Lee, J.; Bagheri, B.; Kao, H. A. (2015), "A Cyber-Physical Systems architecture for Industry 4.0-based manufacturing systems", Manufacturing Letters, Society of Manufacturing Engineers (SME), Vol. 3, pp. 18-23.

Liao, Y.; Deschamps, F.; Loures, E. F.R. et al. (2017), "Past, present and future of Industry 4.0 - a systematic literature review and research agenda proposal", International Journal of Production Research, Taylor \& Francis, Vol. 55, No. 12, pp. 3609-3629.

Mancilha, G.; Gomes, J. (2018), "Comparative analysis between challenges in a brazilian perspective and worldwide initiatives in Advanced Manufacturing", Brazilian Journal of Operatons \& Producton Management, Vol. 15, pp. 209-223.

Mazak, A.; Huemer, C. (2015), “A standards framework for value networks in the context of Industry 4.0", IEEE International Conference on Industrial Engineering and Engineering Management, Vol. 2016, pp. 1342-1346.

Miorandi, D.; Sicari, S.; Pellegrini, F. et al. (2012), "Internet of things: Vision, applications and research challenges", Ad Hoc Networks, Elsevier B.V., Vol. 10, No. 7, pp. 1497-1516.

Moeuf, A.; Pellerin, R.; Lamouri, S. et al. (2018), "The industrial management of SMEs in the era of Industry 4.0", International Journal of Production Research, Taylor \& Francis, Vol. 56, No. 3, pp. 1118-1136.

Monostori, L.; Kádár, B.; Bauernhansl, T. et al. (2016), “Cyber-physical systems in manufacturing", CIRP Annals - Manufacturing Technology, Vol. 65, No. 2, pp. 621-641.

Montanus, M. (2016), "Business Models for Industry 4.0: Developing a Framework to Determine and Assess Impacts on Business Models in the Dutch Oil and Gas Industry", pp. 1-10.

Muhuri, P. K.; Shukla, A. K.; Abraham, A. (2019), "Industry 4 . 0 : A bibliometric analysis and detailed overview", Engineering Applications of Artificial Intelligence, Elsevier Ltd, Vol. 78, No. September 2018, pp. 218-235. 
Müller, J. M.; Kiel, D.; Voigt, K. I. (2018), "What drives the implementation of Industry 4.0? The role of opportunities and challenges in the context of sustainability", Sustainability (Switzerland), Vol. 10, No. 1, available at:https://doi. org/10.3390/su10010247.

Oesterreich, T. D.; Teuteberg, F. (2016), “Understanding the implications of digitisation and automation in the context of Industry 4.0: A triangulation approach and elements of a research agenda for the construction industry", Computers in Industry, Elsevier B.V., Vol. 83, pp. 121-139.

Peng, G.; Jiang, Y.; Xu, J. et al. (2012), “A collaborative manufacturing execution platform for space product development", International Journal of Advanced Manufacturing Technology, Vol. 62, No. 5-8, pp. 443-455.

Pereira, G. B.; Lacerda, A. D. P.; Cleto, M. G. (2018), “Industry 4.0: glitter or gold? A systematic review", Brazilian Journal of Operatons \& Producton Management, Vol. 15, pp. 247-253.

Pereira, P.; Santa-Eulalia, L.; Mosconi, E. (2017), “Industry 4.0: An analysis of existing conceptual frameworks", Vol. 01.

Popkova, E. G.; Ragulina, Y. V.; Bogoviz, A. V. (2019), “Fundamental Differences of Transition to Industry 4.0 from Previous Industrial Revolutions", 169th ed., Springer, pp. 21-29.

Prause, M.; Weigand, J. (2016), "Industry 4 . 0 and Object Oriented Development : Incremental and Architectural Change", Vol. 11, No. Cim, pp. 1-8.

PWC. (2016), Industry 4.0: Building the Digital Enterprise, available at: https://doi.org/10.1080/01969722.2015.1007734.

Qin, J.; Liu, Y.; Grosvenor, R. (2016), “A Categorical Framework of Manufacturing for Industry 4.0 and beyond C3 - Procedia CIRP", Vol. 52, pp. 173-178.

Schluse, M.; Priggemeyer, M.; Atorf, L. et al. (2018), "Experimentable Digital Twins - Streamlining Simulation-based Systems Engineering for Industry 4.0", IEEE Transactions on Industrial Informatics, Vol. 14, No. 4, pp. 1-1.

Schumacher, A.; Erol, S.; Sihn, W. (2016), "A Maturity Model for Assessing Industry 4.0 Readiness and Maturity of Ma- nufacturing Enterprises", Procedia CIRP, available at:https:// doi.org/10.1016/j.procir.2016.07.040.

Shamim, S.; Cang, S.; Yu, H. et al. (2016), "Management approaches for Industry 4.0: A human resource management perspective", 2016 IEEE Congress on Evolutionary Computation (CEC), IEEE, pp. 5309-5316.

Tao, F.; Sui, F.; Liu, A. et al. (2018), "Digital twin-driven product design framework", International Journal of Production Research, Taylor \& Francis, Vol. 7543, pp. 1-19.

Tupa, J.; Simota, J.; Steiner, F. (2017), "Aspects of Risk Management Implementation for Industry 4.0", Procedia Manufacturing, Elsevier B.V., Vol. 11, No. June, pp. 1223-1230.

Uhlemann, T. H.; Lehmann, C.; Steinhilper, R. (2017), “The Digital Twin : Realizing the Cyber-Physical Production System for Industry 4.0", Procedia CIRP, The Author(s), Vol. 61, pp. 335-340.

Vachálek, J.; Bartalský, L.; Rovný, O. et al. (2017), "The Digital Twin of an Industrial Production Line Within the Industry 4.0 Concept", 21st International Conference on Process Control, pp. 258-262.

Xu, L. D.; Xu, E. L.; Li, L. (2018), “Industry 4.0: state of the art and future trends", International Journal of Production Research, Vol. 7543, pp. 1-22.

Yin, Y.; Stecke, K. E.; Li, D. (2018), "The evolution of production systems from Industry 2 . 0 through Industry 4 .0", International Journal of Production Research, Taylor \& Francis, Vol. 7543, pp. 1-14.

Zdravković, M.; Zdravković, J.; Aubry, A. et al. (2017), “Domain framework for implementation of open loT ecosystems", International Journal of Production Research, Taylor \& Francis, Vol. 7543, pp. 1-18.

Zhang, Q.; Cheng, L.; Boutaba, R. (2010), “Cloud computing: State-of-the-art and research challenges", Journal of Internet Services and Applications, Vol. 1 No. 1, pp. 7-18.

Zhong, R. Y.; Xu, X.; Klotz, E. et al. (2017), “Intelligent Manufacturing in the Context of Industry 4.0: A Review", Engineering, Elsevier LTD on behalf of Chinese Academy of Engineering and Higher Education Press Limited Company, Vol. 3, No. 5, pp. 616-630.

Received: 28 Feb 2019

Approved: 06 Apr 2019

DOI: 10.14488/BJOPM.2019.v16.n2.a1

How to cite: Cordeiro, G. A.; Ordónez, R. E. C.; Ferro, R. (2019), "Theoretical proposal of steps for the implementation of the Industry 4.0 concept", Brazilian Journal of Operations \& Production Management, Vol. 16, No. 2, pp. 166-179, available from: https://bjopm.emnuvens.com.br/bjopm/article/view/803 (access year month day). 